\title{
O corpo cúmplice da vida: considerações a partir dos depoimentos de mulheres obesas de uma favela carioca
}

\author{
The body accomplice of life: perception \\ of fat women body from a carioca slum
}

1 Faculdades Federais Integradas de Diamantina. Rua da Glória 187, sala 25, Centro, 39100-000,

Diamantina MG.

vanessa.nutr@ig.com.br

2 Departamento de

Ciências Sociais da Escola

Nacional de Saúde Pública, Fiocruz.

\begin{abstract}
The current article presents conclusions of a developed research in ENSP/Fiocruz, as part of a master degree course, about the relation between poverty and obesity from the symbolic structure seizure around the body. The research had as a goal examining the perception about the body of a fat women group living in a carioca slum, from the use of the qualitative methodology, using the technique of the semi-structured interview. The final researches in this work showed that among the Rocinha women was in force proper standards of body that tied little esthetic attributes. The examined women noticed the obesity in a different way. It was felt through clinical symptoms as for example: "leg pains", "back pains", "lack of breath", "less disposition". It was still possible to observe that the fat body was sometimes valorous among the group, tied to work and the social condition. These results lead us to believe that the obesity assume proper outlines in the different contexts and social groups. For this reason we believe to be necessary the fulfillment of new research dates about the obesity theme in Brazil.
\end{abstract}

Key words Obesity, Poverty, Public health
Resumo O presente artigo apresenta conclusões de uma pesquisa desenvolvida na ENSP/Fiocruz, como parte do curso de mestrado, sobre a relação entre pobreza e obesidade a partir da apreensão da construção simbólica em torno do corpo. A pesquisa teve por objetivo investigar as percepções acerca do corpo de um grupo de mulheres obesas moradoras de uma favela carioca, a partir do emprego da metodologia qualitativa, utilizando a técnica da entrevista semi-estruturada. Os resultados obtidos neste trabalho revelaram que entre as mulheres da Rocinha vigoravam padrões próprios de corpo que pouco se vinculavam a atributos estéticos. A obesidade era percebida de forma diferenciada pelas mulheres investigadas. Ela era sentida através de sintomas clinicos tais como: "dor nas pernas", "dor na coluna”, "falta de ar", "menor disposição". Foi possível, ainda, verificar que o corpo obeso era por vezes valorizado no grupo, vinculando-se ao trabalho e à condição social. Tais resultados nos conduzem a acreditar que a obesidade assume contornos próprios nos diferentes contextos e grupos sociais. Por essa razão, acreditamos ser necessária a realização de novas agendas de investigação sobre a temática da obesidade no Brasil.

Palavras-chaves Obesidade, Pobreza, Saúde pública 


\section{Introdução}

O corpo é um instrumento natural do homem e cada grupo social imprime uma expectativa em torno dele ${ }^{1}$. Para Foucault ${ }^{2}$, em qualquer sociedade o corpo é um lócus de poder, sujeito a coerções e domínios ou a experiências de confronto e resistência. A nosso ver, o corpo se reveste de interpretações e significados. Ao "corpo se aplicam sentimentos, discursos e práticas que estão na base de nossa vida social"’. É através do corpo que os indivíduos se manifestam no mundo e revelam sua posição na sociedade. Dentro dessa perspectiva, o corpo se sobrepõe aos limites do biológico, às condições materiais de vida, e assume também dimensões socioculturais fundamentais. Valores simbólicos relacionados à obesidade podem, dessa for$\mathrm{ma}$, variar entre sistemas e grupos sociais em diferentes contextos históricos 4 , 5, 6. Observa-se atualmente que a corpulência, que no passado já esteve associada à idéia de saúde no imaginário coletivo, tem seu significado completamente transformado em algumas sociedades 5 , 6,7,8. Para Fischler4: [...] há um século nos países ocidentais desenvolvidos os gordos eram amados; hoje, nos mesmos países, amam-se os magros. Padrões definidos para a obesidade assumem, dessa forma, contornos distintos em cada sociedade $4,7,8$.

De acordo com Boltanski 9 , as preocupações relacionadas ao corpo variam entre as camadas sociais. Quanto mais elevada a hierarquia social, maiores são os cuidados estéticos. Nas classes sociais privilegiadas, observa-se o maior consumo de produtos de tratamento para o corpo e a prática de um estilo de vida mais saudável. No Brasil, Lifschitz 10 observou mudanças no imaginário alimentar de segmentos mais favorecidos economicamente, com a emergência do que ele denominou de discursos em torno do "natural". Envolve a proliferação da "boa alimentação" e da escolha de alimentos na sua forma "in natura". Essas ações, segundo Boltanski", podem ser explicadas pela relação mais reflexiva com o corpo por parte desses segmentos, em função do melhor nível educacional e da maior inserção do grupo em ocupações de cunho intelectual. Além disso, para Sobal6 a condição material de vida do grupo permite a adesão a práticas mais saudáveis de vida, tendo em vista os recursos financeiros, assim como a maior flexibilidade de horários e autonomia.

Inversamente, segundo Boltanski ${ }^{9}$, a atenção prestada ao corpo nas classes populares po- de ser menos freqüente. Particularmente neste grupo, o uso do corpo pode compreender uma visão mais utilitária, fruto da importância da força física nas ocupações desempenhadas. Dentro dessa perspectiva, para muitas mulheres das classes populares o corpo pode se apresentar como condição para a produção do trabalho. No cotidiano de luta pela sobrevivência diária - duras e longas jornadas de trabalho, incluindo os afazeres domésticos e os cuidados com os filhos -, o corpo tende a não ser percebido em toda sua plenitude ${ }^{11}$. No Brasil, o estudo de Zaluar12 revelou que para as mulheres das classes populares a obesidade era por vezes valorizada como elemento de força. Silva ${ }^{13}$, por sua vez, verificou em seu estudo com mulheres obesas de baixa renda que a obesidade era um atributo sexual importante no grupo. O corpo erótico e sensual era representado pelas formas arredondadas. Para Muraro 11, as mulheres pobres "não se vêem com seus próprios olhos: elas se vêem com os olhos do homem [...]".

Nesta direção, Popkin ${ }^{14}$ verificou mudanças positivas no padrão alimentar de subgrupos da população norte-americana com melhor nível socioeconômico e, em contrapartida, o surgimento de problemas ligados ao excesso alimentar nos grupos sociais de menor renda do país, especialmente a população hispânica e negra. Ainda segundo Popkin 14, estes grupos tendem a apresentar os índices mais elevados de obesidade nos Estados Unidos. Peña \& Bacallo15, por sua vez, constataram o crescimento da obesidade entre os segmentos mais desfavorecidos nos países latino-americanos e do Caribe.

A perspectiva da construção social do corpo tem servido de fundamento para diferentes trabalhos socioantropológicos12, 13, 16, 17, 18. De acordo com Berger \& Luckmann ${ }^{19}$, sendo a sociedade uma realidade ao mesmo tempo objetiva e subjetiva, qualquer adequada compreensão teórica relativa a ela deve abranger ambos estes aspectos. A partir desta consideração, este estudo buscou uma aproximação com o vocabulário sobre o corpo, a vida, o trabalho e a obesidade em mulheres moradoras da favela da Rocinha, usuárias de uma unidade básica de saúde do município do Rio de Janeiro. $\mathrm{O}$ artigo apresenta conclusões de uma pesquisa desenvolvida na ENSP/Fiocruz, como parte de dissertação de mestrado, sobre a relação entre obesidade e pobreza. O desenho metodológico do trabalho de campo e seus principais resultados são discutidos a seguir. 


\section{Histórias e vivências de vida: a metodologia e o universo social da pesquisa}

A pesquisa qualitativa assume como tarefa central a compreensão da realidade humana vivida socialmente 20 . Neste tipo de metodologia, a preocupação central não é a quantificação, mas sim a compreensão intrínseca de seu objeto de análi$\mathrm{se}^{21}$. Assim, é priorizado um amplo universo de valores, percepções, hábitos e atitudes dos sujeitos. A pesquisa qualitativa busca a superação da análise pautada numa postura quantificadora dos fenômenos sociais, assumindo inicialmente uma postura de confronto frente à atitude tradicional positivista de aplicar ao estudo das ciências humanas os mesmos princípios e métodos das ciências naturais 22 . O modelo qualitativo de análise dos fenômenos privilegia o significado das práticas e escolhas sociais, e não a quantificação dos fenômenos. Neste campo do saber, a realidade social é o próprio dinamismo da vida individual e coletiva com toda a riqueza de significados $[. . .]^{20}$. A pesquisa qualitativa parte do pressuposto de que a consciência é mais condicionada pela inconsciência do que o contrário 23 . São, assim, incorporadas dimensões mais profundas de análise, ou seja, as mediações interiorizadas pelos sujeitos. Para a abordagem social, a realidade representa o próprio dinamismo da vida. O real nunca está acabado, mas em permanente construção, sendo continuamente desdobrado. É este caráter complexo e dinâmico que o permite existir.

O estudo realizou-se entre os anos de 2002 e 2003 no Centro Municipal de Saúde Píndaro de Carvalho Rodrigues, localizado no bairro da Gávea, zona sul do município do Rio de Janeiro. Foram entrevistadas mulheres usuárias do setor de nutrição da unidade e moradoras da favela da Rocinha. O CMS da Gávea, inaugurado em 1976, pertence atualmente à Prefeitura da Cidade do Rio de Janeiro e desenvolve os programas de assistência integral à saúde da criança, do adolescente, da mulher, do adulto e do idoso. Possui uma população adscrita de cerca de 210 mil habitantes 24 e abrange os bairros de Ipanema, Lagoa, Jardim Botânico, Gávea e São Conrado; e, ainda, as comunidades da Rocinha, do Vidigal, Vila Canoas, Parque da Vila da Cidade, Chácara do Céu e Horto. Caracteriza-se por ser uma região extremamente heterogênea, com fortes contrastes sociais, onde residem grupos populacionais de alto poder socioeconômico e outros submetidos a situa- ções de vulnerabilidade social, tais como as comunidades carentes.

O trabalho de campo foi realizado em encontros semanais, totalizando 12 entrevistas. Após traçarmos o diagnóstico da obesidade a partir do parâmetro do Índice de Massa Corporal (IMC), proposto pela Organização Mundial de Saúde - com ponto de corte no valor igual ou superior a $30 \mathrm{~kg} / \mathrm{m}^{2} 25$-, foram levantadas informações sobre as condições de vida e pobreza a partir de uma cesta de indicadores sociais, tal como tem proposto a literatura 26,27 , 28. Esses foram os principais critérios utilizados para a seleção do grupo a ser entrevistado. As entrevistas foram realizadas em sala cedida pelo CMS e seguiram o roteiro de campo redefinido após a realização do pré-teste. Nesta etapa, optamos pela técnica da entrevista semi-estruturada, entendendo por entrevista semi-estruturada aquela que parte de certos questionamentos básicos apoiados em teorias e hipóteses, que interessam à pesquisa e que, em seguida, oferecem amplo campo de interrogativas, fruto de novas hipóteses que vão surgindo à medida que se recebem as respostas do informante 22 . Na etapa de análise do conteúdo, foi realizada a transcrição das entrevistas na íntegra. Posteriormente, foi feita uma leitura flutuante, em que o material transcrito foi lido simultaneamente com a escuta das entrevistas. Em seguida, realizamos uma leitura minuciosa de todo o material, em que foram sublinhadas as idéias principais ligadas à fundamentação teórica. Os temas emergentes foram mapeados e, em seguida, foram então pontuados os aspectos mais importantes a serem discutidos. Por fim, foi elaborada a listagem das respostas das entrevistadas. Para Triviños ${ }^{22}$, os resultados de uma pesquisa só assumem um caráter científico se apresentarem "a coerência, a consistência, a originalidade e a objetivação".

\section{Favela da Rocinha: \\ o espaço social como mosaico}

A favela da Rocinha encontra-se situada no morro Dois Irmãos, na zona sul do município do Rio de Janeiro, ao longo da Estrada da Gávea e do trecho da auto-estrada Lagoa-Barra, que separa os bairros nobres de São Conrado e Gávea, fazendo parte da área de planejamento AP-2. Em 1993, através da Lei no 1995 de 18 de junho, a Rocinha foi outorgada bairro. Os dados acerca do contingente populacional da Rocinha, ainda que controversos, revelam a expansão e o 
desenvolvimento da favela ao longo dos últimos anos. Em 1999, o Iplan-Rio adscreveu 47 mil habitantes. Contudo, a associação de moradores do bairro afirma que a população atualmente é composta de duzentos mil habitantes, com taxas anuais de crescimento de $3,07 \% 29$.

A localização peculiar da Rocinha, próxima ao bairro da Gávea, um dos locais mais nobres da cidade do Rio de Janeiro, impõe aos moradores conviver com diferença sociais marcantes. Mas os contrastes não se limitam apenas aos bairros adjacentes. É possível identificar ainda diferenças internas significativas na favela. A população da Rocinha é composta, sobretudo, de adultos jovens, com um contingente maior de indivíduos do sexo feminino. No que se refere à renda, observou-se uma faixa de rendimentos entre um a cinco salários mínimos. O perfil dos moradores revela, ainda, que a maior parte deles são oriundos da região Nordeste. Quanto às ocupações de trabalho, a população masculina desempenha predominantemente atividades no comércio e na indústria, enquanto as mulheres estão inseridas no setor de serviços, tais como as atividades de doméstica. O perfil de saúde da população da Rocinha caracteriza um quadro sanitário de áreas de aglomeração subnormal, onde as doenças comumente diagnosticadas referem-se a: hepatite A, dengue, doenças diarréicas, respiratórias e de pele 30 .

No que se refere às condições de infra-estrutura, a Rocinha dispõe de rede elétrica fornecida pela Companhia Elétrica Light e existe uma rede parcial da Companhia Estadual de Água e Esgoto (Cedae). A rede de esgotamento sanitário, contudo, não é disponibilizada para todos os moradores. Verifica-se na Rocinha um sistema de saneamento ainda deficiente. A coleta de lixo é realizada pela Companhia de Lixo Urbano (Comlurb), em parceria com os agentes comunitários da favela. Entretanto, a limpeza pública é precária e há o permanente acúmulo de lixo ${ }^{30}$. Ainda segundo o estudo, a estrutura dos domicílios também é heterogênea. Além de barracos, existem casas de alvenaria e cerâmica, e prédios, entre outros tipos de construção. $\mathrm{O}$ acesso a essas habitações ocorre através de becos, ruelas e escadarias irregulares, semelhantes às de áreas faveladas, e, também através da Estrada da Gávea. Nas áreas mais distantes, as partes mais altas da favela, como a denominada Rua 1, e nos sub-bairros mais carentes, como o Barcelos, as condições de saneamento são deficientes. Os domicílios com maior infra-estrutura, no que diz respeito ao acesso a serviços básicos, encontram-se na parte plana da favela, tal como o Largo do Boiadeiro, onde se localiza grande parte do comércio local 30,31 .

A diversidade sociocultural e de infra-estrutura também está presente na Rocinha. $\mathrm{O}$ tamanho e a variedade da Rocinha, considerada a maior favela da América Latina, podem ser percebidos através dos inúmeros estabelecimentos públicos e privados existentes no local. A associação de moradores do bairro estima a existência de 2.500 estabelecimentos comerciais $^{30}, 31,32,33$. No que se refere às atividades de lazer, essa população encontra disponível a praia de São Conrado, o Clube Emoções (casa de shows), a Escola de Samba GRES Acadêmi$\cos$ da Rocinha e, ainda, atividades alternativas dispersas, tais como grupos de teatro, arte, pintura, música; bares e biroscas com espaço para danças nordestinas, como o forró; e bailes populares de funk. Neste sentido, a favela da Rocinha se apresenta como um verdadeiro mosaico socioeconômico e cultural, sendo, portanto, extremamente complexa. A heterogeneidade das favelas cariocas tem sido debatida atualmente por diferentes autores e institutos de pesquisa $^{34,35,36 .}$

\section{Percepções do corpo e a concepção da obesidade}

Entre as doze mulheres entrevistadas, sete apresentaram obesidade classe I (IMC $=30,0$ $\left.34,9 \mathrm{~kg} / \mathrm{m}^{2}\right)$ e cinco obesidade classe II (IMC= $35,0-39,9 \mathrm{~kg} / \mathrm{m}^{2}$ ), com riscos de co-morbidade moderado e grave, respectivamente 25 . No que diz respeito à faixa etária de nosso universo de pesquisa, as mulheres apresentaram idades que variaram entre 34 a 60 anos, com média de idade de 48 anos. A maior parte das mulheres entrevistadas era proveniente da região Nordeste do país. Das doze informantes: quatro eram naturais do estado do Ceará, três da Paraíba, duas da Bahia e uma de Sergipe. Somente duas mulheres revelaram ter vindo de estados da região Sudeste: uma do interior de Minas Gerais e uma do interior do Rio de Janeiro. O perfil das entrevistadas reflete em grande parte o contingente populacional da Rocinha, composto especialmente de nordestinos. Todas as entrevistadas eram moradoras da favela da Rocinha. A árdua vida na terra natal, com o trabalho no roçado, é transformada em um cotidiano igualmente difícil, marcado pela dupla jornada de trabalho, que inclui os afazeres domésticos, os cuidados com os filhos, as ocupações 
do trabalho, a rotina de subir e descer as ladeiras e escadarias da favela, as tensões desencadeadas pela falta de dinheiro, pelo convívio com a criminalidade e a violência. Esta realidade foi expressa freqüentemente através de declarações do tipo: "É muita luta"; "Eu me sinto cansada"; "À noite eu estou morta"; "Exausta”.

$\mathrm{Na}$ análise dos indicadores combinados, que teve por objetivo discriminar mulheres submetidas a condições de vulnerabilidade social, observamos que, no que se refere à cor, as mulheres entrevistadas eram em sua maioria pretas ou pardas. Esta característica está intimamente relacionada à pobreza no Brasil ${ }^{37}$. A baixa escolaridade também é uma característica dos pobres no Brasil. A esse respeito, de acordo com o Núcleo de Estudos de Políticas Públicas da Universidade Estadual de Campinas ${ }^{38}$, mais da metade dos chefes de famílias pobres é analfabeta ou tem no máximo três anos de estudo. As mulheres da Rocinha apresentaram baixo nível educacional: menos de três anos de estudo. Este perfil se relaciona também com menores oportunidades e chances de conquistar postos de trabalho de maior qualificação e melhor condição salarial. Neste sentido, as mulheres se encontravam inseridas em postos de trabalho de menor prestígio, exercendo atividades de diarista, doméstica, costureira, manicure, artesã, entre outras. A precarização do mercado de trabalho impõe ainda o trabalho sem vínculos trabalhistas, em que as mulheres exercem suas atividades sem carteira assinada. A desqualificação das ocupações exercidas por essas mulheres se reflete nos baixos rendimentos: a média salarial observada foi de um a dois salários mínimos mensais. Os arranjos familiares eram múltiplos: existiam núcleos do tipo mulher e cônjuge com filhos; mulher sozinha com filhos ou netos; viúvas sozinhas; e solteiras. E a maior parte das informantes foi considerada chefe do domicílio. Neste sentido, segundo Rocha 37 , famílias chefiadas por mulheres são mais vulneráveis à pobreza. A pobreza é ainda marcadamente associada a condições insatisfatórias de serviços básicos, como a rede de saneamento básico e a limpeza pública. Foi observado déficit no equipamento de infra-estrutura e serviços, o que torna a vida do grupo ainda mais penosa.

O corpo obeso das mulheres da Rocinha denuncia as situações adversas a que estão submetidas em seu cotidiano de vida. A batalha diária de vida inclui os afazeres domésticos, os cuidados com os filhos, o gerenciamento da alimenta- ção da família, o trabalho formal e, ainda, a rotina de subir e descer as ladeiras da favela. Em meio a esse cotidiano de vida, o corpo das mulheres se revela como um corpo para a produção, muitas vezes desapercebido pelo grupo ${ }^{11}$. Neste sentido, as mulheres apreendem a obesidade de múltiplas formas e, até mesmo, afastando-se das concepções usualmente presentes no campo da saúde e da nutrição. A obesidade é uma categoria comumente empregada no meio acadêmico, mas que pode não expressar os diferentes contornos do problema para as mulheres.

As percepções acerca do corpo revelaram que o excesso de peso no grupo se relaciona essencialmente ao aparecimento de sintomas clínicos diversos, à menor agilidade e à menor disposição para o trabalho. Estar obesa para as mulheres da Rocinha é sentir "cansaço"; "falta de ar"; "dores nas pernas"; "problemas na coluna". Algumas mulheres relacionam as transformações do corpo a dois eventos de vida: o casamento e a gravidez: "Foi depois de casar"; "Eu acho que foi depois da gravidez do meu filho". A relação entre gravidez e obesidade feminina tem sido destacada por alguns autores 39 , 40. No entanto, em geral, as alterações nas formas do corpo, com o aumento do peso, são percebidas por intermédio de médicos e profissionais de saúde em consultas de rotina: Quando eu percebi, eu já estava assim, eu nem notei; "Eu vim tratar da pressão, aí a doutora achou que eu estava acima do peso e me mandou pra nutrição; Eu vim à clínica geral e a doutora falou: você tem que perder peso, a senhora está muito acima do peso.

Notadamente, as mulheres da Rocinha não se percebem enquanto obesas, aqui parece vigorar uma imagem corporal distinta da verificada em outros grupos sociais. A obesidade para as mulheres associa-se à pouca energia e à pouca disposição para o trabalho, ao cansaço, à falta de ar, às dores na coluna; raramente se relaciona com atributos estéticos. Entretanto, o corpo magro assume certa ambigüidade. Em oposição ao corpo gordo, o corpo magro é mais ágil: "Você magra faz as coisas rápido, gorda não, cansa". No entanto, se ficar magra é ter maior disposição, pode também significar a privação de alimentos, a doença: "Perder peso é ficar magra, é ficar doente, sem comida.” A valorização do corpo obeso revela-se, portanto, implícita no grupo. Se o corpo magro associa-se à privação de alimentos, à fraqueza e à doença; em contraponto, o corpo obeso passaria a estar vinculado às noções de suficiência alimentar, força e saú- 
de. Entretanto, observa-se que esta concepção é relativizada, ou seja, ao mesmo tempo em que o corpo obeso é desejado por estar relacionado ao vigor e a saúde, também é julgado como "pesado” e, portanto, menos ágil. Nesse aspecto, o corpo magro passa a ser valorizado. Contudo, entre um corpo magro ágil e magro doente, o último parece ser o mais ameaçador, já que para as classes populares a doença é o maior impedimento para a realização do trabalho ${ }^{12}$. Tais concepções revelam a relação do corpo com o trabalho e enfatizam a noção do corpo utilitário, apto à execução das atividades rotineiras e do trabalho informal9.

Ferreira 41 verificou concepções de corpo específicas em sua investigação numa vila de classe popular, localizada na periferia de Porto Alegre. A relação que alguns moradores estabeleciam com o corpo evidenciava a necessidade de distinguir-se de outros que apresentavam o estereótipo da pobreza: corpos sujos, desnutridos, às vezes consumidos pelo álcool, com marcas de violência. Segundo Bourdieu ${ }^{42}$, a sociedade imprime ao corpo princípios de divisão social e de oposição, que são utilizados como forma de justificar a distinção de classe. Neste sentido, o corpo obeso entre mulheres pobres seria uma maneira de diferenciação social em relação ao corpo magro e esbelto das mulheres burguesas.

Nesse contexto, a perda de peso torna-se muito mais uma exigência dos profissionais de saúde do que propriamente uma demanda forte das mulheres: "Eu preciso emagrecer, isso todos os médicos falam." Ao mesmo tempo, a conciliação entre as recomendações médicas e o cotidiano é difícil e, muitas vezes, acaba gerando sentimentos de culpa e impotência: Se eu fizer uma dieta legal, procurar fazer as coisas direitinho, eu perco peso; Eu tenho que levar mais a sério; Eu sou muito desorganizada, eu não almoço na hora certa, eu como qualquer coisa, eu não caminho; Eu acho que foi falta de atenção minha mesmo, se eu tivesse um pouco mais de cuidado, fosse mais atenciosa com que eu como, eu acho que eu ia acabar perdendo. Para Baudrillard43, é nos regimes alimentares que se descortina a pulsão agressiva em relação ao corpo [...]. Nesta perspectiva, o corpo se transforma num objeto ameaçador, que deve ser vigiado e reduzido permanentemente. Segundo Fischler4, para a sociedade de consumo os gordos são percebidos como os únicos responsáveis por sua condição. São gordos "porque comem muito e são incapazes de se controlar". De modo implícito, são julgados socialmente como transgressores das normas e regras. No entanto, pouco a pouco, as mulheres vão revelando os dilemas ligados à superação da obesidade: Com a comida que tenho em casa, eu não consigo; Se eu tivesse um salariozinho melhor pra eu comprar mais coisa que ajudasse; A verdura é muito difícil, nem todo o pobre compra aquele negócio de verdura [...] por isso que eu não faço dieta, porque eu não posso, não posso comer legumes direito.

No entanto, a desigualdade no acesso à alimentação adequada não parece ser o único aspecto relacionado ao corpo obeso. Assim, diante da diversidade de alimentos, os critérios de seleção dos itens parecem se aproximar do padrão de consumo alimentar da infância, especialmente da vida no Nordeste, com a escolha de alimentos próximos ao consumido no roçado. Dessa forma, a memória alimentar se revela no universo de alimentação das mulheres da Rocinha: Eu fui criada na roça comendo isso; $\mathrm{Eu}$ gosto [fritura] porque eu fui acostumada assim; Na roça, a comida é muito pesada, é feita naquela banha; Arroz, feijão [...] dispensa qualquer coisa. Eu acho que é porque eu fui acostumada assim.

O papel do alimento enquanto elemento de conforto para a amenização dos dilemas diários, das angústias, das perdas, das tensões ocasionadas pela falta de recursos, pela violência, pela responsabilidade com a casa e os filhos, também surge na fala das mulheres da Rocinha: Quando eu tô tristinha, eu vou lá e como; Pra mim é nervoso; Eu acho que é muita responsabilidade, agora eu tenho que cuidar de dois filhos, eu tenho que dar conta de duas vidas; Se eu tivesse um horário certo de alimentação, uma dieta balancea$d a$. Orbach 44 se refere a um sintoma singular que, segundo a autora, ocorre em muitos indivíduos com problemas de excesso de peso: a "fome emocional". Diferente da necessidade de saciar a sensação física ocasionada pela falta do alimento, a "fome emocional" diz respeito à utilização da comida para apaziguar inquietações emotivas. Para a autora, os sentimentos são muito parecidos com a comida. Se você dá atenção ao sentimento e se permite vivenciá-lo, ele irá satisfazê-lo ${ }^{44}$. Orbach 44 alerta ainda que muitas vezes a própria sensação de fome amedronta determinados indivíduos, principalmente quando tiveram experiências indesejáveis no passado como, por exemplo, quando não dispunham de comida suficiente na infância. Por essa razão, muitas pessoas comem antes que possam sentir fome. Numa das falas das entrevistadas esse 
comportamento de compensação emocional em situações de privação aparece: [...] quando eu enfartei, eu saí do hospital bem magrinha, devia ter continuado daquele jeito, mas os dias que eu passei lá eu acho que a dieta de lá me fez mal. Claro que não fez, né? Eu falo assim me fez mal pelo olho grande de quando eu saí. Porque lá eu não comia isso, e na minha casa tinha, então eu comia; lá não tinha aquilo, na minha casa tinha, eu comia, entendeu? Aí eu fui engordando, quando eu fui perceber, eu já estava gorda.

\section{Considerações finais}

A seleção de um grupo de mulheres obesas usuárias de um serviço básico de saúde, localizado na região metropolitana do município do Rio de Janeiro, o CMS da Gávea, e moradoras da favela da Rocinha -, submetidas à condição de vulnerabilidade social, foi extremamente útil para reconhecer a complexidade e os diferenciais do perfil de obesidade no país. A pluralidade de circunstâncias vividas pelas mulheres da Rocinha revelou a combinação de elementos materiais, culturais e simbólicos operando na freqüência da obesidade no grupo. Nesta perspectiva, podemos dizer que o coti- diano de vida das mulheres da Rocinha se expressa num perfil de corpo obeso. A obesidade revela também mediações simbólicas importantes. Nesta dimensão, o corpo obeso é o elemento de conforto que ameniza as adversidades vividas no cotidiano em meio à pobreza. Assim, angústias e tensões são aplacadas e delimitam um perfil de excesso de peso. A obesidade apresenta, portanto, múltiplos determinantes. O corpo obeso é, dessa forma, cúmplice da história de vida das mulheres da Rocinha. É através dele que o grupo preserva sua identidade e encontra refúgio para os inúmeros dilemas impostos pela vida, em meio à pobreza e à escassez. Esses resultados chamam a atenção para a apreensão da obesidade enquanto uma face da pobreza urbana no Brasil. Neste sentido, torna-se importante sinalizar a necessidade da criação de novas agendas de pesquisa e ensino capazes de sistematizar, à luz de evidências empíricas e aprofundamento conceitual, novas abordagens sobre as relações entre obesidade, pobreza e saúde. A realização de investigações que viabilizem a aproximação com a experiência da obesidade de maneira plural e interdisciplinar pode favorecer um olhar compreensivo sobre o problema e, também, alternativas de enfrentamento.

\section{Colaboradores}

VA Ferreira foi responsável pela elaboração, redação e revisão do artigo. $R$ Magalhães participou da orientação da pesquisa, elaboração e revisão do artigo.

\section{Referências}

1. Mauss M. Sociologia e antropologia. São Paulo: Edusp, EPU; 1974.

2. Foucault M. Vigiar e punir: nascimento da prisão. Petrópolis: Vozes; 1997.

3. Ferreira J. O corpo sígnico. In: Minayo MCS, Alves PC, organizadores. Saúde e doença: um olhar antropológico. Rio de Janeiro: Fiocruz; 1994. p. 101-12.

4. Fischler C. Obeso benigno, obeso maligno. In: Sant' Anna DB, organizador. Políticas do corpo: elementos para uma história das práticas corporais. São Paulo: Estação Liberdade; 1989. p. 69-80.

5. Cassidy CM. The good body: when big is better. Med Anthropol 1991; 13(3):181-214.

6. Sobal J. Obesity and socioeconomic status: a framework for examining relationship between physical and social variables. Med Anthropol 1991; 13(3):231-47.

7. Brown PJ, Konner M. An anthropological perspective on obesity. In: Goodman AH, Dufour DL, Pelto GH, editors. Nutritional anthropology: biocultural perspectives on food and nutrition. Mountain View: Mayfield Publishing Company; 1999. p. 347-58. 
8. Wolf N. O mito da beleza: como as imagens de beleza são usadas contra as mulheres. Rio de Janeiro: Rocco; 1992.

9. Boltanski L. As classes sociais e o corpo. Rio de Janeiro: Graal; 1979

10. Lifschitz J. Alimentação e cultura: em torno ao natural. Physis - Rev Saúde Col 1997; 7(2):69-83.

11. Muraro RM. Sexualidade da mulher brasileira: corpo e classe social. Petrópolis: Vozes; 1983.

12. Zaluar A. A máquina e a revolta: as organizações populares e o significado da pobreza. 2a ed. São Paulo: Brasiliense; 1985.

13. Silva DO. O fiel da balança na história do corpo obeso em mulheres de baixa renda [dissertação]. Rio de Janeiro: Escola Nacional de Saúde Pública, Fundação Oswaldo Cruz; 1997.

14. Popkin BM. The nutrition transition in low-income countries: an emerging crisis. Nutr Rev 1994; 52(9): 285-98.

15. Peña M, Bacallao J. La obesidade en la pobreza: un problema emergente en las Américas. In: Peña M, Bacallao J, organizadores. La obesidad en la pobreza: un nuevo reto para la salud publica. Washington, DC: Organización Panamericana de la Salud; 2000. p. 3 11. (Publicación Científica no 576).

16. Aguirré P. Aspectos socioantropológicos de la obesidad en la pobreza. In: Peña M, Bacallao J, organizadores. La obesidad en la pobreza: un nuevo reto para la salud publica. Washington, DC: Organización Panamericana de la Salud; 2000. p. 13-25. (Publicación Científica no 576).

17. Tonial SR. Desnutrição e obesidade: faces da desigualdade social no acesso aos alimentos e nas representações do corpo [tese]. Rio de Janeiro: Escola Nacional de Saúde Publica, Fundação Oswaldo Cruz; 2001.

18. Velho OG. Relatório do grupo de pesquisa do Museu Nacional: Projeto Hábitos Alimentares em Camadas de Baixa Renda. Rio de Janeiro: Museu Nacional/ UFRJ; 1977.

19. Berger PL, Luckmann T. A construção social da realidade: tratado de sociologia do conhecimento. Petrópolis: Vozes; 1973.

20. Minayo MCS. Pesquisa social: teoria, método e criatividade. 9a edição. Petrópolis: Vozes; 1998.

21. Lévis-Strauss C. Introdução à obra de Marcel Mauss. In: Mauss M. Sociologia e antropologia. São Paulo: Edusp, EPU; 1974. p. 1-36.

22. Triviños ANS. Introdução à pesquisa em ciências sociais: a pesquisa qualitativa em educação. São Paulo: Atlas; 1987.

23. Demo P. Introdução à metodologia da ciência. 2a edição. São Paulo: Atlas; 1987.

24. Prefeitura do Rio de Janeiro. Secretaria Municipal de Saúde. Sigab/Datasus. Relatório de distribuição de tipos de consultas individuais por especialidade para o período 01/01/01 a 31/12/01: CMS Pindaro de Carvalho Rodrigues. Rio de Janeiro: Secretaria Municipal de Saúde; 1998.

25. World Health Organization. Obesity: preventing and managing the global epidemic: report of WHO consultation on obesity. Geneve: WHO; 1997.

26. Sen AK. Desigualdade reexaminada. Rio de Janeiro: Record; 2001.

27. Salama P, Destremau B. O tamanho da pobreza: economia política da distribuição de renda. Rio de Janeiro: Garamond Universitária; 1999.
28. Townsend P. The international analysis of poverty. New York: Harvester Wheatsheaf; 1993.

29. Tv-Roc 2001. Disponível em: http: www.tvroc.com.br

30. Prefeitura do Rio de Janeiro. Secretaria Municipal de Saúde. Unidade de Cuidados Primários de Saúde Dr. Albert Sabin. Estudo gerencial da UACPS Dr. Albert Sabin. Rio de Janeiro: Secretaria Municipal de Saúde; 2001.

31. Rotenberg S. Práticas alimentares e o cuidado da saúde da criança de baixo peso [dissertação]. Rio de Janeiro: Instituto Fernandes Figueira, Fundação Oswaldo Cruz; 1999.

32. União Pró-Melhoramentos dos Moradores da Rocinha. Varal de lembranças: histórias e causos da Rocinha. Rio de Janeiro: Tempo e Presença; 1983.

33. Segala L. O riscado do balão japonês: trabalho comunitário na Rocinha (1977-1982) [dissertação]. Rio de Janeiro: Programa de Pós-Graduação em Antropologia Social do Museu Nacional, Universidade Federal do Rio de Janeiro; 1991.

34. Lima JM. Pesquisa socioeconômica das comunidades de baixa renda no município do Rio de Janeiro. Rio de Janeiro: Instituto de Pesquisa Econômica e Aplicada; 1998. (Série Seminários no 20/9).

35. Preteceille E, Valladares L. A desigualdade entre os pobres: favela, favelas. In: Henriques R, Organizador. Desigualdade e pobreza no Brasil. Rio de Janeiro: Instituto de Pesquisa Econômica Aplicada; 1999. p. 459-85.

36. Instituto Superior de Estudos da Religião. Consumo sobe as favelas. O Globo, 2002; 2 set (Caderno Rio): 10-11.

37. Rocha S. Caracterização da pobreza no Brasil. In: O Brasil no fim do século: desafios e propostas para ação governamental. Rio de Janeiro: Instituto de Pesquisa Econômica Aplicada; 1994. p. 37-43

38. Núcleo de Estudos de Políticas Públicas. Família e pobreza: relatório final. Campinas: Convênio FecampIpea, Unicamp; 1992

39. Kac G, Velasquez-Melendez G, Valente JG. Menarca, gravidez precoce e obesidade em mulheres brasileiras selecionadas em um centro de saúde de Belo Horizonte, Minas Gerais, Brasil. Cad Saúde Pública 2003; 19(1):111-18.

40. Lins APM. Fatores associados ao sobrepeso em mulheres de 20 a 59 anos no município do Rio de Janeiro [dissertação]. Rio de Janeiro: Instituto Fernandes Figueiras, Fundação Oswaldo Cruz; 1999.

41. Ferreira J. Cuidados do corpo em vila de classe popular. In: Duarte FD, Leal OF, organizadores. Doença, sofrimento, perturbação: perspectivas etnográficas. Rio de Janeiro: Ed. Fiocruz; 1998. p. 49-56

42. Bourdieu P. A economia das trocas simbólicas. São Paulo: Perspectiva; 1992.

43. Baudrillard J. A sociedade de consumo. Rio de Janeiro: Elfos; Lisboa: Edições 70; 1995.

44. Orbach S. Sobre a comida: reaprenda a comer e mude sua vida. Rio de Janeiro: Record; 2003.

Artigo apresentado em 7/12/2005

Aprovado em 9/01/2006

Versão final apresentada em 9/01/2006 